\title{
THE UBIQUITY AND UTILITY OF RESISTANCE: Codesign and Personalization of Information Systems
}

\author{
Melanie Wilson \\ University of Manchester \\ Manchester Business School \\ Manchester, UK
}

\begin{abstract}
In assessing the positive and negative connotations of ubiquity, this paper favors association with cohabitation and domestication of technology rather than colonization and domination. Unpredicted user responses to technology are often framed as resistance. Despite its ubiquity, resistance remains a neglected topic in information systems research, and belief in technology as "the one true way" of solving a problem means that it will often be demonized. Recognition of the powerful nature of IS elucidates sources of resistance: the policies governing the behavior and reactions of users to technology will impinge on the range of user activities deemed to be recalcitrant. This is especially important with the types of technology involved in ubiquitous information environments as they are often used outside of organizations for leisure and social activities. However, one cannot assume that newer mobile technologies deployed to achieve organizational goals will be adopted and used by employees with the degree of success that these technologies have enjoyed in voluntary environments. An alternative approach is advocated: resistance is perceived not as a threat, but as a site for personalization, and local adaptation; users' subversive acts can play a role in improving the technology; IS failure can be lessened and resistance may ultimately play a role in stabilizing a system. Finally, an argument is made for personalization through user-driven codesign as part of a strategy of utilizing resistance.
\end{abstract}

Keywords Resistance, acceptance, personalization, domestication, innofusion, critical, codesign 


\section{INTRODUCTION}

Portable artifacts, wireless communication, and wallet-sized smart cards-new mobile information technology may herald an era of endless activity, devoid of the boundaries that previously protected the haven of detached time. With technology keeping indolence at bay, users remain permanently connected, easily detected, and inescapably contactable - never absent or idle. Readings of the progressive nature of such developments hinge on assumptions about the willingness of users to adopt the technologies and the way of life they inaugurate. Whatever the technical design of the environment for usage, the social and political context of a change situation constitute major factors in the successful implementation of technology. To improve future innovations, we need to learn the lessons of past implementations. The argument in this paper is that the codesign of ubiquitous socio-technical systems remains desirable, with those who carry out the work orchestrating adaptations. As shall be shown, this standpoint challenges the negativity of managerialist and technocratic discourse concerning resistance and acceptance.

The term ubiquity can imply the occupation and colonization of local environments by dominating powers. The notion of codesign then becomes a crucial consideration. This paper pursues the critical call that "the control of technology by those affected by it remains a desirable agenda" (Bauer 1995, p. 1). At the same time, by revealing the ubiquity of resistance, the reader is to be persuaded that noncompliance is an inevitable consideration for implementers. Correlating personalization with the adaptation of technology to local needs reveals the positive role and innovative potential of recalcitrance. The suggestion here is that this alternative view of resistance forms the basis of strategies for dealing with local reactions to new technology in ubiquitous information environments. This conclusion is reached by recognizing the prescriptions contained in imposed technology, and that such an imposition invites subversion. In all of this, user responses to new socio-technical ensembles need to be contextualized in terms of their mandatory or volitional environments.

To overcome the bias toward managerialism that infuses much of the writing on employee responses to innovation, a critical perspective is employed to rethink technology acceptance via an engagement with literature on resistance. The position of this paper builds on earlier alternative approaches to resistance (Hirschheim and Klein 1989; Hirschheim and Newman 1988; Markus 1983), while bringing in Waddell and Sohal's (1998) observation that "there is a strong case that suggests that resistance should not be approached adversarilly because it can play a useful role in an organizational change effort" (p. 544). Adopting a multidisciplinary approach, the view of user agency described herein recognizes the power relations in organizations where legitimacy of behavior is circumscribed by project sponsors.

The paper is structured as follows. First, existing critical literature on resistance to information systems, technology, and change is reviewed. Second, resistance is framed within a political comprehension of organizational realties. Third, an alternative rational view of resistance is described. Fourth, the creative aspects of resistance are delineated. In conclusion, the contribution to the conference themes and a critical agenda are described. 


\section{USER AND EMPLOYEE RESISTANCE TO TECHNOLOGY AND CHANGE}

\subsection{The Critical Information Systems Literature on Resistance}

The influential Information Systems literature on resistance contains seeds of what has become identified as a critical approach. Often containing emancipatory aims, criticality entails a challenge to existing patterns of power and authority, critiquing technological determinism, highlighting the subjective nature of information, and demonstrating the existence of managerialist perspectives dominating approaches to IS (Howcroft and Trauth 2004). Within the set of writings that explicitly recognized the political and conflictual nature of systems development within organizations (for example, Franz and Robey 1984; Lyytinen 1987; Newman and Noble 1990), Markus' (1983) seminal paper, in particular, pointed to assumptions about resistance as a function of the political reality of organizations. The power plays involved in the acceptance process have been explored more recently by Cendon and Jarvenpaa (2001) and Doolin (2004), while Brown et al. (2002) suggest that power and political issues associated with implementation may be influential in driving resistance to new technology. On this theme, Munkvold (1999) offers us an account of users' rationale for resisting a new IS.

In directing attention to the perspective of the user, and thereby underscoring the marginalization of recalcitrant users, Hirschheim and Newman (1988) highlight the implicit managerialist approach to acceptance that still pervades treatment of nonacceptance. Hirschheim and Klein (1989) further this revelation of perspectives, reminding us that designers have their own world views which steer them toward identification of different problems and solutions. Lyytinen (1987) and Robey et al. (1993) provide studies of differences in perspectives between systems developers and potential users, thereby offering some explanation for the resistance phenomena. Markus and Bjørn-Andersen (1987), and Beath and Orlikowski (1994) have deconstructed the tensions that underlie the developer-user relationship. Marakas and Hornik (1996), meanwhile, examined the dissonance between stated support for a system and actual resistance to that system.

In relation to IFIP Working Group 8.2 conferences, of late there have been a variety of papers focusing on resistance (for example, Allen and Kern 2001; Sorensen et al. 2001; Tapia 2004; Whitley and Hosein 2001; Wilson 2002; Wilson and Howcroft 2000). This may be explained by the increasing recognition of the ubiquity of resistance.

\subsection{The Ubiquity of Resistance in Organizations}

Resistance to change is always possible (Trader-Leigh 2002) and constitutes the little-recognized but critically important contributor to the failure of change projects (Waddell and Sohal 1998). Organizational theory tells us that resistance is built into the nature of organizations, thanks to the inertia that permits greater reliability and predictability (Waddell and Sohal 1998). So, the tendency toward stability and away 
from risk means individuals will defend the status quo, thereby confronting change. In addition, people do not happily accept the domination of others: "There is a general tendency among those subject to power and control to resist by challenging the systems and rules imposed on them" (Doolin 2004, p. 352). This accounts for Schein's (1998) observation that resistance to change in organizations may be one of the most ubiquitous of organizational phenomena. In relation to IS on a global level, variance in technological development can be largely explained by the existence of resistance (Mokyr 1990), and even with strong closure around a technological framework, resistance trhives (McLaughlin et al. 1999)

\subsection{Resistance: A Loaded Term}

Despite the ubiquity of resistance in organizations and its influence on technological developments (Mokyr 1990), this multifaceted phenomenon (Ansof 1988) still remains a curious topic of study in a discipline where the very phenomena of study, information systems, instigate change and leave upheaval in their wake. Resistance is viewed as a structural or a personal deficit, irrational, morally bad, and ultimately futile (Bauer 1995). Zaltman and Duncan (1977, p. 63) define resistance as any conduct that serves to maintain the status quo in the face of pressure to alter the status quo. However, resistance is a loaded term. In the context of new technology, it is used in an accusatory fashion, serving mainly to blame those who resist, and often implying a managerial and technocratic bias (Bauer 1995). ${ }^{1}$

The treatment of resistance by those engaged in IS development or research inherits much from organizational theory and management research, where it has a history of receiving a very bad press (Waddell and Sohal 1998). Most commonly linked with negative employee attitudes or with counter-productive behaviors (e.g., Brown et al. 2002), resistance is also associated with the introduction of unanticipated delays and costs instabilities to the process of strategic change (Ansof 1988). The notion of utility in resistance remains overlooked (Waddell and Sohal 1998). Likewise, in technology and innovation studies, the term, resistance elicits contradictory connotations, loaded with a managerial and modernization bias (Bauer 1995). In addition, there is a tendency to focus only on so-called technical issues, at the expense of the social; yet political, social, economic, technical, and organizational factors are interwoven into ICT systems (Dutton et al. 1995).

From the perspective of IS professionals, it may well be that the IS group in an organization simply cannot understand the resistance on the part of the users (Brown et al. 2002). Bauer (1995, p. 13) argues that the managerial discourse inherent in the treatment of resistance proves that "rationality is claimed by the designer, and actions that challenge his or her proposal are "resistance""; those who employ the designer assume a Tayloristic "one best way." Overall, an attitude exists whereby all technological projects are seen as a legitimate tribute to great human achievements, ignoring the complementary stories that need to be told.

${ }^{1}$ Historically, and in stark contrast, Resistance stands for the clandestine (and morally praiseworthy) insurgence against an occupying, illegitimate power during World War II. 


\section{POWER AND RESISTANCE}

To overcome the managerial bias surrounding the study of noncompliance, a critical approach undertakes an examination of the political context of technological deployment in order to explore how environmental and political factors impact technology acceptance attitudes and behaviors (Brown et al. 2002). This also permits an understanding of the forces that give rise to, define, and discipline resistance.

\subsection{Interests, Scripts and Quiet Politics}

Understanding resistance to IS innovation implies examination of the organizational distribution of power, not just factors inherent to the system (design features) and factors inherent to the person (subjective norm and perceived behavioral control) (Brown et al. 2002 , p. 293). Organizational and economic interests are likely to be reflected in the particular configuration of an information system (Shaiken 1986) and so, in return, information systems are likely to support and enhance the interests of a minority who already are in more powerful situations (Hirschheim and Klein 1989; Markus and BjørnAndersen 1987). Within the context of power relations in organizations, IS play a crucial role in mediation, especially during times of change.

In addition, the control aspects of information systems have implications for issues of power and inequality in organizations (Knights and Murray 1997). When stabilized, an information system may become a powerful media through which daily routines of the organization are orchestrated. Information systems can change work practices, and inscribe a moral order (Bloomfield 1991). Technology is perceived as an intermediary, employed as a change agent to bring about behavior required by those sponsoring the development project-such as standardization (Berg and Bowker 1997; Hanseth et al. 1996). This implies that information systems incorporate particular assumptions and particular world views (Hirschheim and Klein 1989) rather than some objective set of facts about the organization. Information systems are implemented with the intended effect that operatives behave in accordance with their agenda or script (Wilson 2002). These "quiet politics" should be investigated to see how they arouse resistance and how they become embedded in information infrastructure, embodying particular values, policies and modes of practice (Bowker et al. 1995).

\subsection{Legitimacy, Resistance, and Retribution}

In contrast to the attention paid to the existence and exercise of power through the technology, acts of resistance by the non-legitimate, marginalized, and less-powerful actors have been largely disregarded (Wilson 2002). Yet resistance bears witness to conflict, can take many forms, and implies that power and domination are never total: they are processes, rather than permanently achievable states. We need also to consider the anticipated and actual consequences one may experience in response to acts of resistance. Resistance is a form of risky behavior (Bauer 1995). A person who violates norms and rules runs the risk of exclusion, punishment, and material sanctions. 
Elsewhere, this reality has been related to dysfunctional organizational culture where a practice of "shoot the messenger" means that the politics of blame pervade. Given the hierarchical nature of most management structures, no one wants to be the harbinger of bad news and thus top management rarely directly receives news of slippage. This culture of non-reporting of doubts, flaws, and failures to senior management in organizations, argue Dutton et al. (1995), obfuscates the creation of a climate where organizational learning can take place and prevents remedial action from being taken. This would suggest the need for a different approach to dissent.

\subsection{Acceptance, Mandatory and Volitional Contexts}

To improve our understanding of technology acceptance, we need to scrutinize active policies toward usage. In recognizing the political realities of organizational life, we are concerned with distinguishing between mandatory and voluntary contexts, since the policies governing the behavior and reactions of users to the technology will impinge on the range of user activities deemed to be recalcitrant. This is especially important with the types of technology involved in ubiquitous information environments as they are used outside of organizations, often for leisure or social activities. However, one cannot assume that newer mobile technologies deployed to achieve organizational goals will be adopted and used by employees with the same degree of success that the same technologies have enjoyed in leisure or voluntary environments.

In the IS literature, user responses have typically been evaluated via user satisfaction, focusing on attitudes toward the outputs of a system and the IS group, rather than that of using the system (Brown et al. 2002). The major technique for measuring and understanding acceptance is the technology acceptance model (TAM), which has been used by a number of authors in IS (Adams et al. 1992; Agarwal and Prasad 1997; Davis 1989; Davis and Venkatesh 1996). According to TAM, other things being equal, the easier the system is to use, the more useful it will be. A more critical approach to the use of TAM is offered by Brown et al. (2002), who argue that the model is limited because of context: the research was conducted in environments in which adoption was voluntary. This is key, since, as we have seen, issues of power and resistance hinge on the notion of consent. ${ }^{2}$

As Brown et al. describe, the decision to implement a new IT architecture within a firm results in individual users having limited, if any, control over the implications of this decision. Users will eventually be offered limited choices in the software available and, therefore, will be forced to comply with the decisions of others. Given this context, the validity of the TAM is put in question when the behavior is mandatory: "A mandatory use environment is defined here as one in which users are required to use a specific technology of system in order to keep and perform their jobs" (Brown et al. 2002, p. 283). And despite the fact that people appear to use the technology, this does not mean that their attitude is not one of resentment, which may display itself elsewhere.

${ }^{2}$ Other research on acceptance has also suffered from such bias: the theory of reasoned action focuses entirely on volitional behavior. 
It is possible to have an effective information system without positive attitudes or satisfaction on the part of users. But the negative attitudes will have potentially profound consequences in a mandatory situation. Mandated use can lead to users delaying or obstructing the implementation; resenting, underutilizing, or sabotaging the new system; or separating from the organization (Brown et al. 2002).

As Turner (1990) warns, the imposition of a system of control almost inevitably invites its subversion. The levels of prescriptions are also embodied in technologies: the more prescriptive they are, the more constraints on users' behavior, increasing subversive acts. Legitimate interaction is dictated by the script of the technology. Additionally, although there is a continuum of voluntariness, user perceptions of voluntariness will vary (Brown et al. 2002).

We can take the example of smart card technology to examine the significance of voluntary and mandatory environments for adoption/non-adoption issues. Smart cards are to be understood as personal, portable, flexible, secure tokens that form an integral part of a larger information infrastructure. They have a range of uses in voluntary arenas such, as supermarket shopping and access to transport systems. As such they are relatively noncontroversial (although there were more concerns during their earlier rollout). Contrast this to the UK government's plans for national identity cards operating on a similar technology, but resistance to the proposed technology seems inevitable. For the government, the technologies were a justifiable mandatory technology. ${ }^{3}$ However, opponents argued that the proposals are flawed on political, technical, and financial grounds and constituted an ineffective response to the problems of security and fraud, while posing an unacceptable threat to civil liberties. ${ }^{4}$

Alternatively, users may be able to elect to use a technology or not-even in mandated environments (Brown et al. 2002). ${ }^{5}$ The crucial issue is whether there are alternatives or not, and access to an earlier system or way of working may decrease the possibilities of stabilization (Wilson and Howcroft 2002). In both Munkvold's (1999) and Doolin's (2004) longitudinal studies, usage of the technology was never mandatory and choice was possible. Combined with earlier mistrust of implementers, the users chose the older substitute. The risk of non-stabilization may increase with time rather than decrease, depending on levels of support, as is seen in the cases of Munkvold and of Wilson and Howcroft (2002), where a spiral downward was created as early adopters rejected the technology. McLaughlin et al. (1999) recount the struggle to secure a central place for the new system in the work practices of the staff located outside the

${ }^{3}$ To enable the fight against crime and terror, prevention of fraud, a halt to illegal immigration, a stop identity theft, to move the UK into line with Europe with the government claiming that the innocent had nothing to fear (Home Office, www.homeoffice.gove.uk/ comrace/identitycards).

${ }^{4}$ The latter has meant a challenge from the Judicial Court of Human Rights, questioning issues concerning storage of information, the entry of information otherwise available, obtaining information from documents not designated for this purpose, the entry on the register by compulsion, issues of disclosure of information, and issues of authorization for collection and disclosure of information (Home Office, www.homeoffice.gove.uk/comrace/identitycards).

${ }^{5}$ The exception being broad-scope systems such as ERP systems, where employees do not have a decision regarding use. 
center, who associated the earlier system with autonomy at the local departmental level. These power issues relate also to the tension between global systems and local user needs.

\section{RATIONAL VIEW OF RESISTANCE TO CHANGE AND TECHNOLOGY}

The negative perspective and adversarial approach that dominates treatment of resistance have little theoretical support (Waddell and Sohal 1998). From a user perspective, there is likely to be some rationale for resistance, including imperfect technology whose flaws can be subsequently revealed by resistance. This is a functional view of resistance. Properly directed, resistance can improve design and ensure stability. Indeed, Mokyr (1990) observes that, to historians, resistance can act as a force that shapes technology. These issues are now explored.

\subsection{Rationale for Resistance}

Resistance is far more complex than previously thought (Munkvold 1999). It is a function of a variety of social factors, and can, contrary to managerial discourse, stem from a rational fear of detrimental effects to individual interests (Hirscheim and Newman 1988). At the same time, the nonrational factors are only nonrational from the perspective of another (Lyytinen 1987). Usually treated as sinister, even the negative political factors, such as favoritism and point-scoring, have a rationale of their own for the individuals concerned. Krovis (1993) argues that if changes are considered negative by organizational members, then there is likely to be resistance, which in turn will have ramifications on the success of the information system, and on the ability of the organization to deal with IS-related change.

With the increased penetration of computers in society comes increased reasons for resistance, yet the common-sense assumption that the object of resistance is technology should be challenged. Bauer (1995) suggests that causes relate to antecedents, which are often ignored due to concentration on the process of resistance and effects. In order to understand what is being resisted and why, research should investigate social, cultural, and organizational context, resistor's perspectives of (negative) effects. Resistance can be directed against technical devices because they are a symbolic focus of what infringes on people's livelihood-the traditional meaning of Luddism or machine breaking. In the case of IS, then, we should make a distinction between resistance to computers/computerization (hardware), resistance to types of applications (software), resistance to new work practices, ${ }^{6}$ and resistance to the (political) consequences of the innovation.

${ }^{6} \mathrm{We}$ may want to extend this to include the implications of ubiquitous information environments as this may mean an end to the boundaries between work and leisure (Wilson and Greenhill 2004). 
Where supporters of a new system may see only irrationality, alternative justifications underpinning acts of resistance include reduced autonomy, lack of involvement, lack of felt need, bonds to existing technologies, and adoption costs (Munkvold 1999, p. 265). The sizeable number of variables deemed to have direct relevance to resistance to change is significant in accounting for the ubiquity of resistance (Trader-Leigh 2002).

\subsection{Resistance as Indicator of Alternatives}

The questionable notions of progress and the technocratic discourse noted above can be challenged by acts of resistance. Resistance points out that it is a fallacy to believe change itself to be inherently good. We know that a design is necessarily bounded within constraints of space and time (Simon 1981), and so the notion of a single best solution-rationality writ large - is hardly justifiable since "under any constraint, different assumptions suggest different solutions and legitimate the 'resistance' to a single best design" (Bauer 1995, p. 13). Hence, resistance also encourages the search for alternative methods and outcomes (Waddell and Sohal 1998), a critical source of innovation and a testament to the fallacy of the "one best way."

\subsection{Resistance as the Pain of Innovation}

Resistance can also be seen as the acute pain of the innovation process (Bauer 1995), a signal, warning of things that should be examined (Waddell and Sohal 1998). It is naive to assume that a change process that occurs only with minimal resistance must have been a good change and managed well; evidence of resistance can be a useful window into underlying tensions (Trader-Leigh 2002). Resistance can be used to secure a sustainable future - a tool to negotiate the change versus status quo boundary (Waddell and Sohal 1998). Resistance balances demands for change against the need for constancy and stability. On the creative front, resistance brings with it an influx of energy. Apathy is not a good response to change, whereas resistance can be harnessed: "With resistance and conflict comes the energy or motivation to seriously address the problem at hand" (Waddell and Sohal 1998, p. 545).

\section{THE PRODUCTIVE ASPECTS OF RESISTANCE}

\subsection{Local Resistance to Adapt and Stabilize Standard Systems}

Given the importance of the implementation stage, and the fact that local consequences are almost certainly likely to differ from consequences in distant places, an information system may well be stabilized in one location, yet destabilized upon implementation elsewhere. McLaughlin et al. (1999) concur with the open nature of the information system, noting that the systems they studied were reopened and reshaped, 
and that "attempts to close the lid will only be successful where managers recognize the distinction between standardized use and integration of the system, and local versions of its stabilization by different groups" (p. 224).

In relation to personalization, this paper seeks to underline the importance of context for interactions and responses by users to socio-technical ensembles by differentiating between mandatory and volitional environments. This is because personalization requires examination of organizational distribution of power (Brown et al. 2002). In particular, we emphasize that within work organizations, users will be more likely to experience a mandatory environment. However, the comments made could be extended to more user-driven innovations. Second, we argue that personalization may be improved by the adoption of a less confrontational stance toward subversive acts, incorporating such innovations as part of a user-driven codesign strategy where resistance is utilized.

Within large, distributed organizations, issues of personalization will overlap more strongly with localization, although elsewhere they may be treated as distinct phenomena. In such (mandatory) environments, the possibilities of personalization are related to innofusion: the adaptation of technology to suit local needs. This endorses a view of the innovative characteristic of recalcitrant behavior. McLaughlin et al. recognize the fundamental tension that managers have to resolve: the move to standardize the system on the one hand, and the need to respond to the requirement to localize the system on the other. Relating resistance to the regulation of users, local practices can be analyzed for their role in mediating regulatory control from central management. We might ask, how far can local practices be regarded as a form of resistance to new technologies? Yet this need not be framed negatively since "frequently, initial resistance by staff to new technology turns out to have facilitated the ultimate stabilization of a system" (McLaughlin et al. 1999, p. 222). Strong resistance to new procedures by users ensured modification of the system, accommodating most of the users' demands. Similarly, Munkvold (1999) sees implementation as a process of maturation. He implicitly acknowledges that in distributed organizations the resistance will be from the local, where IS successes will be enabled if adaptation at a local level is permitted.

Given the political nature of IS development in organizations and our critical emphasis on human agency and emancipation with regard to the issue of user resistance, this opens the door to ask questions about the right to control technological development. The first step in direct control is to ensure people obtain the technology they prefer. In more volitional environments, ubiquitous computing systems aspire to offer a more personalized (and presumably better) experience, in return for the disclosure of some personal information by the users of the systems. However, the personalized is limited to the menu of possibilities envisaged by the designers. It does not allow for the users to develop something more original and creative.

\subsection{Codesign: Participation or Managing Resistance?}

Resistance behavior continues to be an unmanaged process (Trader-Leigh 2002). Waddell and Sohal (1998) suggest a thoroughly positive approach, arguing for actively utilizing resistance to stabilize the change process. The difficulty of organizational 
change is exacerbated by the management of resistance, derived from a simple set of assumptions and misunderstandings of recalcitrance. This adversarial approach needs to be replaced with one that retains the possibility of benefitting from resistance. Techniques need to be extended to carefully manage change and to utilize resistance, with an emphasis on communication, feedback, and teamwork.

In the past, codesign has been on the model of participation and enrolment as a means to involve users in the development process. Participative approaches are advocated where resistance is expected to be high and it is intended to lower noncompliance by increasing the commitment to change (Waddell and Sohal 1998). The degree to which participation is an "authentic process" varies from the inspiring and genuine workers input enabled by the early Scandinavian School (see, for example, Nygaard 1992), through to tokenism and even authoritarianism (Howcroft and Wilson 2003b). Nevertheless, it is unlikely that without industrial action workers could insist on participation where management was averse to a more democratic work form. Hence the paradox of terms, such as "empowerment," since the control by management of the boundaries of power reveals that the participation process is itself controlled by management and, therefore, cannot lead to an equality of input (Howcroft and Wilson 2003a). In the main, participation is not quite the same as utilizing resistance. The behavior of users in repugning technology is likely to be framed in terms of their deficiencies in understanding the benefits (Munkvold 1999; Wilson 2002; Wilson and Howcroft 2000, 2002). Less authentic participative forms can end up being a one-way marketing process, including battering the users with information, and a misunderstanding of user needs (McLaughlin et al. 1999). "Though these techniques may be categorized as participative in form, they are far from participative in nature. They amount to little more than an exercise in salesmanship and clearly illustrate an adversarial management mindset" (Waddell and Sohal 1998, p. 546). Reporting mechanisms should perhaps allow users to establish how the technology is best suited to them and the way they carry out their work.

\section{CONCLUSION}

This paper contributes to the study of technology adoption and non-adoption by setting out to rethink our biased views toward resistance. It is thus critical in nature (Howcroft and Trauth 2004) with its underlying emancipatory aims: it seeks to emphasize that ubiquity does not equate to colonization but rather cohabitation. Further, it explicitly recognizes the political nature of organizations, intending to upset existing patterns of power and authority. It entails a critique of technological determinism, and highlights and challenges the managerialist perspective that pervades the treatment of resistance to date. In their stead, a more constructive language is offered in association with resistance, and the validity, usefulness, and indispensability of challenging new, yet untried solutions is suggested.

In offering a critical approach to the literature on resistance to technology and organizational change, the paper sought to remind the IS community of lessons we have yet to learn from past experience with IS development. It is hoped that this will inform the approach to new phenomena brought about the ubiquitous nature of new information 
environments. In rethinking technology acceptance, the paper have challenged many traditional assumptions about organizations, computing, and work insofar as they relate to resistance. It also touched on the issue of personalization from the perspective of codesign consisting of local modifications in a process of innofusion, replacing negative views about non-conformity and usage. The work now is to provide concrete examples of adoption and resistance, with users placed center stage and the account analyzed with the theoretical insights entailed in the paper.

\section{REFERENCES}

Adams, D. A., Nelson, R. R., and Todd, P. A. "Perceived Usefulness, Ease of Use, and Usage of Information Technology: A Replication," MIS Quarterly, (16:2), 1992, pp. 227-247.

Agarwal, R., and Prasad, J. "The Role of Innovation Characteristics and Perceived Voluntariness in the Acceptance of Information Technologies," Decision Sciences, (28:3), 1997, pp. 557 582.

Akrich, M. "The De-scription of Technical Objects," in Shaping Technology/Building Society, W. E. Bijker, and J. Law (Eds.), Cambridge, MA: MIT Press, 1992.

Allen, D., and Kern, T. "Enterprise Resource Planning Implementation: Stories of Power, Politics, and Resistance," in New Directions in Information Systems Development, B. Fitzgerald, N. Russo, and J. I. DeGross (Eds.), Boston: Kluwer Academic Publishers, 2001, pp. 149-162.

Ansof, I. The New Corporate Strategy, New York: John Wiley \& Sons, 1988.

Bauer, M. (Ed.). Resistance to New Technology, Cambridge, UK: Cambridge University Press, 1995.

Beath, C. M., and Orlikowski, W. J. "The Contradictory Structure of Systems Development Methodologies: Deconstructing the IS-User Relationship in Information Engineering," Information Systems Research (5:4), 1994, pp. 350-377.

Berg, M. And Bowker, G. "The Multiple Bodies of the Medical Record: Towards a Sociology of an Artifact," The Sociological Quarterly (38:3), 1997, pp. 513-538.

Bloomfield, B. P. "The Role of Information Systems in the UK National Health Service: Action at a Distance and the Fetish of Calculation," Social Studies of Science, (21:4), 1991, pp. 701734.

Bowker, G. C., Timmermans, S., and Star, S. L. "Infrastructure and Organizational Transformation: Classifying Nurses' Work," in Information Technology and Changes in Organizational Work, W. Orlikowski, G. Walsham, M. R. Jones, and J. I. DeGross (Eds.), London: Chapman and Hall, 1995, pp. 344-370.

Brown, A.A., Massey, A.P., Montoya-Weiss, M. M., and Burkman, J. R. "Do I Really Have To? User Acceptance of Mandated Ttechnology," European Journal of Information Systems (11), 2002, pp. 283-295.

Cendon, B. V., and Jarvenpaa, S. L. "The Development and Exercise of Power by Leaders of Support Units in Implementing Information Technology-Based Services," Journal of Strategic Information Systems (10) 2001, pp. 121-158.

Davis, F.D. "Perceived Usefulness, Perceived Ease of Use, and User Acceptance of Information Technology," MIS Quarterly (13:3), 1989, pp. 319-340.

Davis, F.D., and Venkatesh, V. "A Critical Assessment of Potential Measurement Biases in the Technology Acceptance Model: Three Experiments," International Journal of HumanComputer Studies (45), 1996, pp. 19-45.

Doolin, B. "Power and Resistance in the Implementation of a Medical Management Information System," Information Systems Journal, (14), 2004, pp. 343-362. 
Dutton, W. H., MacKenzie, D., Shapiro, S., and Peltu, M. Computer Power and Human Limits: Learning from IT and Telecommunications Disasters, PICT Policy Research Paper No. 33, Edinburgh University, UK, 1995.

Franz, C. R., and Robey, D. "An Investigation of User-Led Systems Design: Rational and Political Perspectives," Communications of the ACM (27:12), 1984, pp. 1202-1209

Hanseth, O., Monteiro, E., and Hatling, M. "Developing Information Infrastructure: The Tension between Standardization and Flexibility," Science, Technology and Human Values (21), 1996, pp. 407-426.

Hirschheim, R. A., and Klein, H. K. "Four Paradigms of Information Systems Development," Communications of the $A C M(32: 10), 1989$, pp. 1199-1216.

Hirschheim, R. A., and Newman, M. "Information Systems and User Resistance: Theory and Practice," Computer Journal (31:5), 1988, pp. 398-408.

Howcroft, D., and Trauth, E. "The Choice of Critical Information Systems Research," in Relevant Theory and Informed Practice, B. Kaplan, D. Truex, D. Wastell, A. T. WoodHarper, and J. I. DeGross (Eds.), Boston: Kluwer Academic Publishers, 2004, pp. 195-211.

Howcroft, D., and Wilson, M. "Paradoxes of Participatory Design: The Janus Role of the Systems Developer," Information and Organizations (13:1), 2003a, pp. 1-24.

Howcroft, D., and Wilson, M. "Participation: 'Bounded Freedom' or the Hidden Constraints on User Involvement," New Technology, Work and Employment (18:1), 2003b, pp.2-19.

Knights, D., and Murray, F. "Markets, Managers, and Nessages: Managing Information Systems in Financial Sservices," in Information Technology in Organizations: Strategies, Networks, and Integration, B. P. Bloomfield, R. Coombs, D. Knights, and D. Littler (Eds.), Oxford, UK: Oxford University Press, 1997.

Krovis, R. "Identifying the Causes of Resistance to IS Implementation," Information and Management (25), 1993, pp. 327-335.

Lyytinen, K. "Different Perspectives on Information Systems: Problems and Solutions," $A C M$ Computing Surveys (19:1), 1987, pp. 5-46.

Marakas, G. M., and Hornik, S. "Passive Resistance Misuse: Overt Support and Covert Recalcitrance in IS Implementation," European Journal of Information Systems (5), 1996, pp. 208-219.

Markus, M. L. "Power, Politics and MIS Implementation," Communications of the $A C M(26: 6)$, 1983, pp. 430-444.

Markus, L., and Bjørn-Andersen, N. "Power Over Users: Its Exercise by Systems Professionals," Communications of the ACM (30:6), June 1987, pp. 498-504.

McLaughlin, J., Rosen, P., Skinner, D., and Webster, A. Valuing Technology: Organizations, Culture and Change, London: Routledge, 1999.

Mokyr, J. The Lever of Riches: Technological Creativity and Economic Progress, New York: Oxford University Press Inc., 1990.

Munkvold, B. E. "Challenges of IT Implementation for Supporting Collaboration in Distributed Organizations," European Journal of Information Systems (8), 1998, pp. 260-272.

Nygaard, K. "How Many Choices Do We Make? How Many Are Difficult?" in Proceedings of the Software Development and Reality Construction Conference, C. Floyd, H. Züllighoven, R. Budde, and R. Keil-Slawik (Eds.), Berlin: Springer-Verlag, 1992, pp. 52-59.

Newman, M., and Noble, F. "User Involvement as an Interaction Process," Information Systems Research (1:1), 1990, pp. 89-113.

Robey, D., Smith, L., and Vijayasaaarathy, L. R. "Perceptions of Conflict and Success in Information Systems Development projects," Journal of Management Information Systems (10:1), 1993, pp. 123-139.

Sauer, C. Why Information Systems Fail: A Case Study Approach, Oxfordshire, UK: Alfred Waller, 1993.

Schein, E. Organizational Psychology, London: Prentice Hall, 1998. 
Shaiken, H. Work Transformed: Automation and Labor in the Computer Age, New York: Lexington Books, 1986.

Simon, H. A. Administrative Behavior ( $4^{\text {th }}$ ed.), New York: Simon and Schuster, 1997.

Sorensen, C., Whitley, E. A., Madon, S., Klyachko, D., Hosein, I., and Johnstone, J. "Cultivating Recalcitrance in Information Systems Research," in New Directions in Information Systems Development, B. Fitzgerald, N. Russo, and J. I. DeGross (Eds.), Boston: Kluwer Academic Publishers, 2001, pp. 297-316.

Tapia, A. H. "Resistance or Deviance? A High-Tech Workplace During the Bursting of the DotCom Bubble," in Relevant Theory and Informed Practice, B. Kaplan, D. Truex, D. Wastell A. T. Wood-Harper, and J. I. DeGross (Eds.), Boston: Kluwer Academic Publishers, 2004, pp. 577-596.

Trader-Leigh, K. E. "Case Study: Identifying Resistance in Managing Change," Journal of Organizational Change (15:2), 2002, pp. 138-155.

Turner, G. British Cultural Studies ( $2^{\text {nd }}$ ed.), London: Routledge, 1990.

Waddell, D., and Sohal, A. S. "Resistance: A Constructive Tool for Change Management," Management Decision (36:8), 1998, pp. 543-548.

Whitley, E. A., and Hosein I. "Doing Politics Around Electronic Commerce: Opposing the Regulation of Investigatory Powers Bill" in New Directions in Information Systems Development, B. Fitzgerald, N. Russo, and J. I. DeGross (Eds.), Boston: Kluwer Academic Publishers, 2001, pp. 415-438.

Wilson, M. "Rhetorics of Enrolment and Acts of Resistance: Information Technology as Text," in Global and Organizational Discourse about Information Technology, E. H. Wynn, E. A. Whitley, M. D. Myers, and J. I. DeGross, Boston: Kluwer Academic Publishers, Massachusetts, 2002, pp. 225-248.

Wilson, M., and Howcroft, D. "The Role of Gender in User Resistance and IS Failure," in The Social and Organizational Perspective on Research and Practice in Information Technology, R. Baskerville, J. Stage, and J. I. DeGross (Eds.), Boston: Kluwer Academic Publishers, 2000, pp. 453-471.

Wilson, M., and Greenhill, A. "Gender and Teleworking Identities in the Risk Society: A Research Agenda," New Technology, Work and Employment (19:3), 2004, pp. 207-221.

Wilson, M., and Howcroft, D. "Re-conceptualizing Failure: Social Shaping Meets IS Research," European Journal of Information Systems (11:4), 2002, pp. 236-250.

Zaltman, G., and Duncan, R. Strategies for Planned Change, Toronto: Wiley, 1977.

\section{ABOUT THE AUTHOR}

Melanie Wilson is a senior lecturer in Management Information Systems at the Manchester Business School, University of Manchester, UK. Her current research interests include critical approaches to information systems; resistance, adoption, and failure of information systems; gender and information technology; and at-home telework. Her publications can be found in Information and Organization, Journal of Strategic Information Systems, Information Technology and People, European Journal of Information Systems, Journal of Information Technology, and New Technology, Work and Employment. A trained linguist, she also has industrial experience in the export manufacturing sector. Melanie can be reached at Melanie.Wilson@manchester. ac.uk. 


\section{Part 6}

\section{Position Papers}

